\title{
Medium Perfusion Flow Improves Osteogenic Commitment of Human Stromal Cells
}

\author{
Alice Pasini $\left(\mathbb{D},{ }^{1}\right.$ Joseph Lovecchio $\mathbb{D}^{1},{ }^{1,2}$ Giulia Ferretti, ${ }^{1}$ and Emanuele Giordano $\mathbb{D}^{1,2,3}$ \\ ${ }^{1}$ Laboratory of Cellular and Molecular Engineering "S. Cavalcanti," Department of Electrical, Electronic, and Information \\ Engineering "G. Marconi” (DEI), Alma Mater Studiorum-University of Bologna, Cesena, Italy \\ ${ }^{2}$ Advanced Research Center on Electronic Systems (ARCES), Alma Mater Studiorum-University of Bologna, Bologna, Italy \\ ${ }^{3}$ BioEngLab, Health Science and Technology, Interdepartmental Center for Industrial Research (HST-CIRI), Alma Mater Studiorum- \\ University of Bologna, Ozzano Emilia, Italy
}

Correspondence should be addressed to Joseph Lovecchio; joseph.lovecchio@unibo.it

Alice Pasini and Joseph Lovecchio contributed equally to this work.

Received 31 October 2018; Revised 4 February 2019; Accepted 1 March 2019; Published 2 May 2019

Academic Editor: Stefan Arnhold

Copyright (C) 2019 Alice Pasini et al. This is an open access article distributed under the Creative Commons Attribution License, which permits unrestricted use, distribution, and reproduction in any medium, provided the original work is properly cited.

\begin{abstract}
Dynamic culture protocols have recently emerged as part of (bone) tissue engineering strategies due to their ability to represent a more physiological cell environment in vitro. Here, we described how a perfusion flow induced by a simple bioreactor system improves proliferation and osteogenic commitment of human bone marrow stromal cells. L88/5 cells were cultured in poly(methyl methacrylate) custom-milled communicating well plates, in the presence of an osteogenic cocktail containing $1 \alpha$,25-dihydroxyvitamin D3, L-ascorbic acid 2-phosphate, and $\beta$-glycerophosphate. The dynamic cell culture was maintained under perfusion flow stimulation at $1 \mathrm{~mL} / \mathrm{min}$ for up to 4 days and compared with a static control condition. A cell viability assay showed that the proliferation associated with the dynamic cell culture was $20 \%$ higher vs. the static condition. A significantly higher upregulation of the osteogenic markers runt-related transcription factor 2 (RUNX2), collagen type I (COL1A1), osteocalcin (BGLAP), alkaline phosphatase (ALPL), and osteopontin (SPP1) was detected when the perfusion flow stimulation was administered to the cells treated with the osteogenic cocktail. An in silico analysis showed that in the dynamic cell culture condition (i) the shear stress in the proximity of the cell layer approximates $10^{-3} \mathrm{~Pa}$, (ii) the nutrient and the waste product concentration is more homogeneously distributed than in the static counterpart, and (iii) perfusion flow was associated with higher nutrient consumption. In summary, increased cell proliferation and enhanced early phenotype commitment indicate that dynamic cell culture conditions, delivered via bioreactor systems, produce an enhanced in vitro environment for both basic and translational research in tissue engineering and regenerative medicine.
\end{abstract}

\section{Introduction}

Obtaining more physiological stem cell (SC) culture conditions to support in vitro cell expansion and/or to prompt a phenotype commitment of interest is a valuable objective for both basic and translational research. In this respect, the ability to provide cell cultures with adequate nutrient supply and waste removal and to administer specific physical cues as differentiating signals would foster the study of molecular SC physiology and be relevant for the design of efficient protocols in tissue engineering (TE) and regenerative medicine (RM). Indeed, the main drawback in traditional static cell cultures is the lack of the sustained native diffusive exchanges. This constraint might both affect the cell availability of glucose, an important nutrient for the generation of cellular energy, and consistently determine the accumulation of toxic metabolites such as lactate that could inhibit cell growth [1]. In this respect, including a perfusion flow would provide to the cells a more physiological environment $[2,3]$. Moreover, besides increasing cell seeding and viability, fluid perfusion-induced shear stresses were demonstrated to also drive osteogenic phenotype commitment [4- 


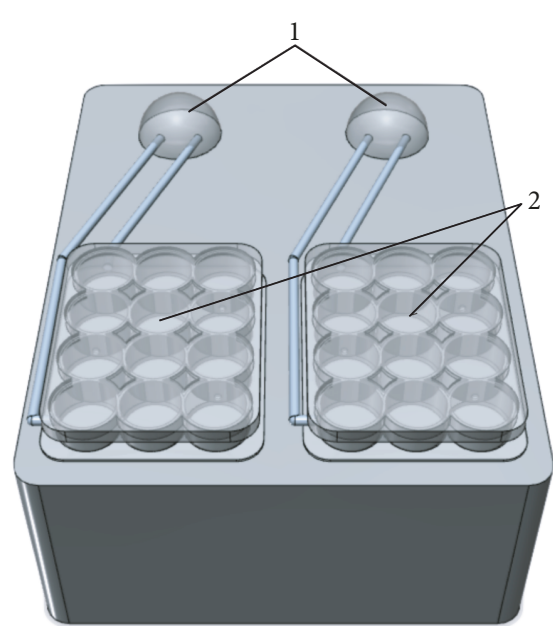

(a)

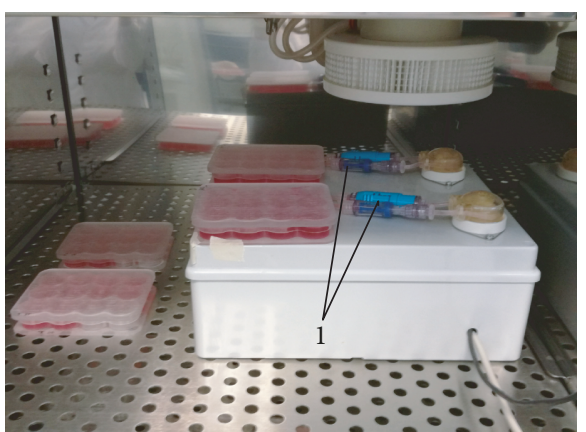

(b)

Figure 1: Bioreactor system layout. (a) Front view sketch of the bioreactor system: "1," peristaltic pumps and "2," custom PMMA culture plates. (b) Actual prototype: “1," Spiros ${ }^{\circledR} /$ MicroClave $^{\circledR}$ connectors.

7], which is otherwise traditionally obtained via supplementation to the culture medium of osteogenic soluble factors, such as ascorbic acid, dexamethasone, and $\beta$-glicerophosphate [8]. Therefore, the aim of this study is to propose a dynamic cell culture approach via an elementary custom perfusion device, hereafter referred to as a bioreactor system, and evaluate its effects on proliferation and early osteogenic commitment of a human bone marrow stromal cell line. Indeed, an in vitro enhancement of the proliferation and differentiation of SC towards the osteogenic phenotype would result in a more efficient platform for scientific research, while accelerating the biological process of osteogenesis would boost the cell therapy paradigm. The in vitro analysis will be complemented by an in silico study of dynamic culture-imposed conditions to explore if diffusive exchanges and fluid-dependent shear stress values are consistent with the observed biological outcomes.

\section{Materials and Methods}

2.1. Bioreactor System Architecture. A bioreactor system was designed and built to generate perfusion flow to sustain cell culture. To this aim, two autoclavable WELCO WPM2S1EACP (WELCO Co. Ltd., Tokyo, Japan) peristaltic pumps, sketched in Figure 1(a)-1, were implemented to promote constant medium delivery to/removal from the cell culture with a perfusion flow rate tunable from a range of 1 to $5 \mathrm{~mL} / \mathrm{min}$.

Custom culture chambers, reported in Figure 1(a)-2, were milled in poly(methyl methacrylate) (PMMA, Altuglas ${ }^{\circledR}$ CN 100 10000, Altuglas International, La Garenne-Colombes Cedex, France) - a cheap, easily malleable material, whose biocompatibility for biomedical applications has already been shown [9] - following the geometry of a standard 12well plate (h12 mm, $\varnothing 22 \mathrm{~mm})$. Holes $(\varnothing 2 \mathrm{~mm})$ were drilled between adjacent wells, according to the scheme reported in Figure 2(a), to allow medium to flow through. Two PMMA custom-milled communicating well plates (Figure 1(a)-2) can operate independently to allow comparison of control and osteogenic media supply. Each plate hosts ten glass coverslips maintained under a continuous medium flow.

Each chamber works as an independent detachable unit integrated into a perfusion line via Spiros ${ }^{\circledR} / \mathrm{MicroCLAVE}^{\circledR}$ (ICU Medical Inc., San Clemente, CA, USA) connectors, useful to avoid medium leakage and contamination risk during its disconnection from the device for specific evaluations, such as cell observation under the light microscope. Disposable/biocompatible tubes (i.e., Tygon ${ }^{\circledR}$ silicon tubing) are used as perfusion line.

A simple control unit (Figure 2(b)) was implemented in order to manage the device. An EasyDriver (SparkFun Electronics, Boulder, CO, USA) stepper motor driver operates as a guide of the two peristaltic pumps. Two DPDT Mini Power Switches (Lynxmotion Inc., Mirabel, QC, Canada) and four colored LEDs (SparkFun Electronics) are used to allow "play (green)," "pause (red)," "filling (yellow)," or "perfusion (blue)" function surveillance. An Arduino UNO was programmed to control all the components of the device. In this study, a perfusion flow rate of $1 \mathrm{~mL} / \mathrm{min}$ was administered, but this parameter can be easily adapted from a range of 1 to $5 \mathrm{~mL} / \mathrm{min}$, by programming the Arduino UNO at the beginning or during the experiments.

In its final layout, the prototypal bioreactor system shown in Figure 1(b) displays a unibody case (119, w24, and $\mathrm{h} 9 \mathrm{~cm})$. The device is designed to operate inside a standard cell culture incubator that will maintain physiological $\mathrm{pH}$ and temperature.

2.2. Cell Culture and Osteogenic Induction. The human bone marrow stromal L88/5 cell line (a kind gift of Prof. Jeanette Maier) was cultured in RPMI 1640 (Euroclone S.p.A., Pero, MI, Italy) supplemented with $10 \%$ fetal bovine serum, $2 \mathrm{mM}$ L-glutamine, $100 \mathrm{U} / \mathrm{mL}$ penicillin, and $100 \mathrm{mg} / \mathrm{mL}$ streptomycin, at $37^{\circ} \mathrm{C}$ in a humidified $5 \% \mathrm{CO}_{2}$ incubator. Cells were seeded on standard polystyrene plates or on glass coverslips $(\varnothing 18 \mathrm{~mm})$ at a density of $10^{5} \mathrm{cells} / \mathrm{cm}^{2}$ and 


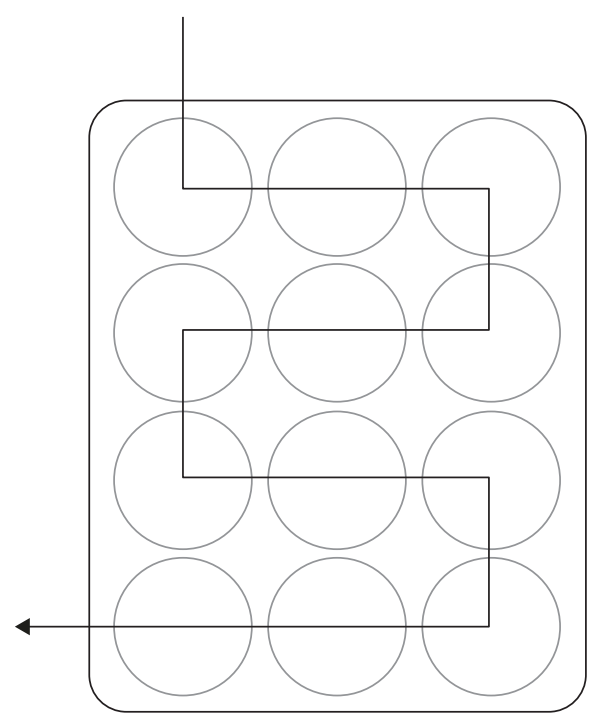

(a)

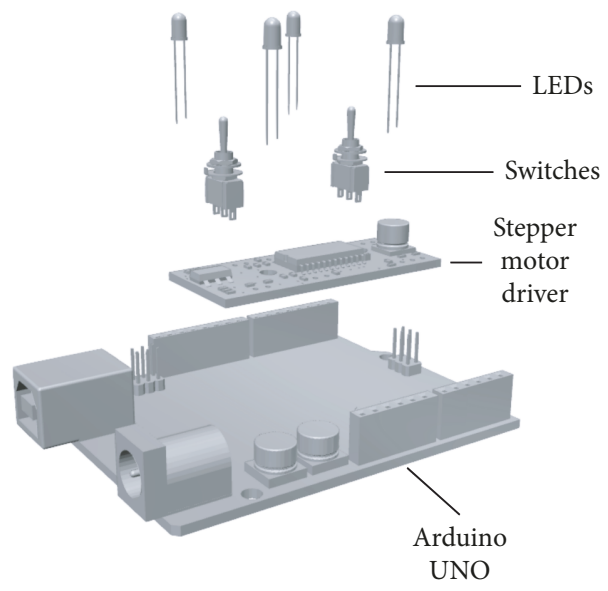

(b)

FIGURE 2: (a) Schematic representation of medium flow direction through the custom PMMA culture plate. (b) Schematic representation of the components of the control unit.

allowed to grow for $48 \mathrm{~h}$ to reach confluency. Glass coverslips with confluent cells were then carefully transferred via the use of tweezers to the multiwell PMMA custom-milled plates and cultured in dynamic and static conditions. Cells were stimulated with vehicle or osteogenic differentiation cocktail containing $20 \mathrm{nM} 1 \alpha, 25$-dihydroxyvitamin D3 (D1530, Sigma-Aldrich, Milano, Italy), $50 \mu \mathrm{M}$ L-ascorbic acid 2-phosphate (49752, Sigma-Aldrich), and $10 \mathrm{mM} \beta$ glycerophosphate (50020, Sigma-Aldrich), with media replaced every $48 \mathrm{~h}$. At indicated time points, cells were then processed for biological analysis.

2.3. Cell Viability Assay. To test their proliferation, L88/5 cells were seeded on glass coverslips $(\varnothing 10 \mathrm{~mm})$ at a density of $5000,10,000$, and 20,000 cells $/ \mathrm{cm}^{2}$ and allowed to adhere overnight. The day after, the coverslips were transferred to (i) PMMA custom-milled communicating well plates, (ii) PMMA custom-milled noncommunicating well plates, and (iii) standard polystyrene well plates. After 48 and $72 \mathrm{~h}$ of cell culture, cell viability was assessed using PrestoBlue ${ }^{\circledR}$ Cell Viability Reagent (A13261 Invitrogen, Thermo Fisher Scientific, Waltham, Massachusetts, USA) following the manufacturer's instructions and using a standard curve to compare experiments. Data are reported as mean value \pm SEM of six coverslips from two independent biological replicates.

2.4. Gene Expression Analysis. Quantitative real-time PCR (qPCR) was used to analyze the mRNA expression level of the osteogenic marker genes osteocalcin (BGLAP), alkaline phosphatase (ALPL), osteopontin (SPP1), runt-related transcription factor 2 (RUNX2), collagen type I (COL1A1), and osteonectin (SPARC). After 2, 4, and 10 days of stimulation with the osteogenic cocktail, total RNA was extracted using the NucleoSpin ${ }^{\circledR}$ RNA (Macherey-Nagel GmbH \& Co. KG,
Düren, Germany) following the manufacturer's instructions. $500 \mathrm{ng}$ of total mRNA was reverse transcribed to cDNA with the iScript ${ }^{\mathrm{TM}}$ cDNA Synthesis Kit (170-8891, Bio-Rad, Segrate, MI, Italy). $5 \mu \mathrm{L}$ of the $1: 10$-diluted $\mathrm{cDNA}$ was then amplified by qPCR using the SsoAdvanced ${ }^{\mathrm{TM}}$ SYBR $^{\circledR}$ Green Supermix (172-5261, Bio-Rad). KiCqStart ${ }^{\circledR}$ SYBR $^{\circledR}$ Green Primers (Sigma-Aldrich) were used (H_B2M_1, H_GAPDH_1, H_RUNX2_1, H_COL1A1_2, H_BGLAP_1, H_SPP1_1, and H_SPARC_1). qPCR experiments were performed in duplicate using the CFX Connect ${ }^{\mathrm{TM}}$ Real-Time PCR Detection System (Bio-Rad) using a two-step protocol $\left(2 \mathrm{~min}\right.$ at $95^{\circ} \mathrm{C}, 40$ cycles of $5 \mathrm{~s}$ at $95^{\circ} \mathrm{C}$, and $30 \mathrm{~s}$ at $60^{\circ} \mathrm{C}$ ) followed by a melting step between 95 and $65^{\circ} \mathrm{C}$. Data analysis was conducted using the CFX Manager ${ }^{\mathrm{TM}}$ Software (Bio-Rad), creating a gene study that uses an interrun calibrator to normalize the variability between the experiments. Data are reported as mean value \pm SEM of at least three independent biological replicates.

2.5. Finite Element Modeling of Nutrient/Waste Diffusion in Dynamic Cell Culture. A Finite Element Model (FEM) (COMSOL Multiphysics ${ }^{\circledR}$ Modeling Software, Stockholm, Sweden) was implemented to investigate fluid velocity profile, shear stress, nutrient consumption, and waste production in static vs. dynamic condition during a 3-day cell culture. The computational model was obtained using primitive geometries and Boolean operations. The whole 12communicating-well plate (Figure 3(a)) was simulated to study fluid velocity profile. On the other hand, shear stress and nutrient/waste dynamics were calculated using a single well volume (Figure 3(b)). The single well specifications were $\varnothing 22 \mathrm{~mm}$ and $\mathrm{h} 7.4 \mathrm{~mm}$; whereas, the single coverslip (Figure 3(b)-1) was $\varnothing 5 \mathrm{~mm}$ and h0.1 mm. The inlet/outlet diameter was $1.6 \mathrm{~mm}$. 


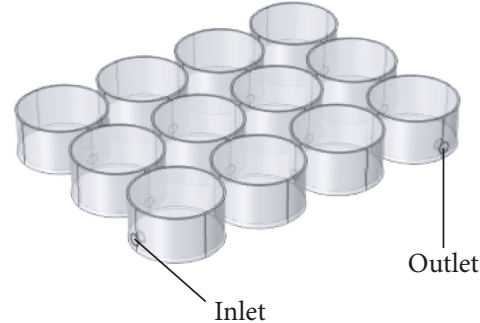

$\underset{y_{\mathbb{R}}}{z} x$

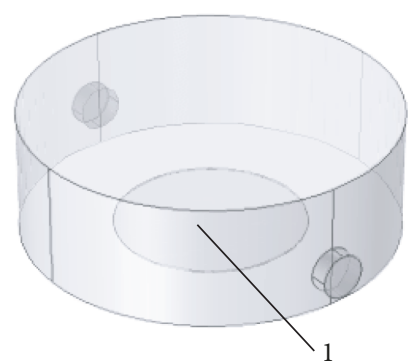

$\underset{y_{*}}{z} x$

(a)

(b)

FIgURE 3: Three-dimensional modeling of the culture unit. (a) PMMA custom-milled communicating well plate. (b) Single well: "1," glass coverslip.

TABLE 1: Mass transport parameters.

\begin{tabular}{lcc}
\hline Parameters & Values & Units \\
\hline Glucose (initial) & 0 & $\mathrm{~mol} / \mathrm{m}^{3}$ \\
Waste (initial) & 0 & $\mathrm{~mol} / \mathrm{m}^{3}$ \\
Nutrient consumption & $4.74 E-12$ & $\mathrm{~mol} / \mathrm{s}$ \\
Waste production & $3.4 E-12$ & $\mathrm{~mol} / \mathrm{s}$ \\
Nutrient diffusion coefficient & $3.9 E-9$ & $\mathrm{~m}^{2} / \mathrm{s}$ \\
Waste diffusion coefficient & $1.6 E-9$ & $\mathrm{~m}^{2} / \mathrm{s}$ \\
\hline
\end{tabular}

To approximate the medium properties, the inner volume of the well was modeled as water. Laminar flow, based on Navier-Stokes equations (equation 1), was set up as the physics for the dynamic condition. A velocity of $0.0027 \mathrm{~m} / \mathrm{s}$ (flow rate $1 \mathrm{~mL} / \mathrm{min}$ ) was used:

$$
\left\{\begin{array}{c}
\rho \frac{D \vec{u}}{D t}=-\vec{\nabla} p+\mu \nabla^{2} \vec{u}+\rho \vec{g} \\
\vec{\nabla} \cdot \vec{u}=0,
\end{array}\right.
$$

where $\rho$ is the density, $u$ the velocity, $t$ the time, $p$ the pressure, $\mu$ the viscosity, and $g$ the gravitational acceleration.

Mass transport, based on the second Fick law (equation 2) was modeled for both static and dynamic regimens:

$$
\frac{\partial c}{\partial t}=D \frac{\partial^{2} c}{\partial x^{2}}
$$

where $c$ is the concentration, $t$ the time, $D$ the coefficient diffusion, and $x$ the location in the medium.

A sensitivity study of the mesh was performed in order to obtain the most computationally efficient solution. Specific parameters were derived in [10] as reported in Table 1.

Flow rate values of 1,2 , and $5 \mathrm{~mL} / \mathrm{min}$ were tested aiming to estimate the shear stress values occurring at the bottom of the custom PMMA well and the nutrient consumption.

2.6. Statistical Analysis. Statistical analysis was performed using the GraphPad Prism 6 software. Data are presented

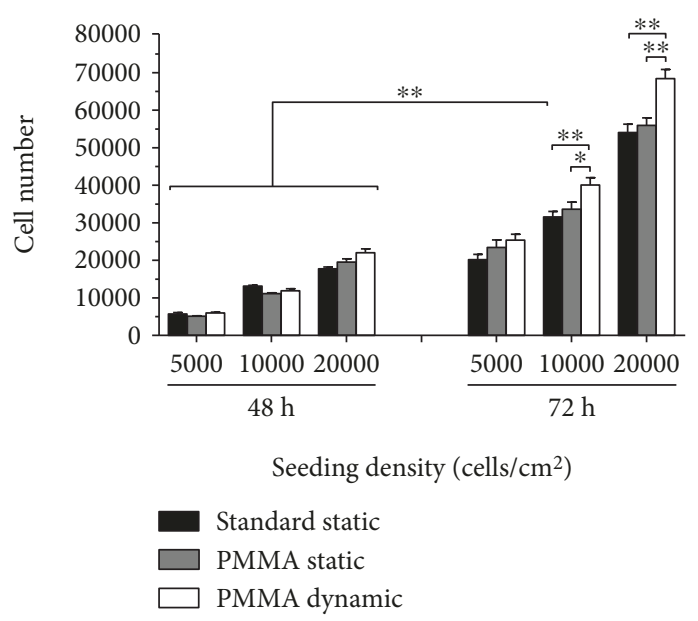

FIgURe 4: Effect of static and dynamic cell culture conditions over L88/5 cell proliferation. Cell viability of L88/5 cells, seeded at a density of $5000,10,000$, and 20,000 cells $/ \mathrm{cm}^{2}$ and cultured in standard polystyrene or custom PMMA plates, was evaluated at 48 and $72 \mathrm{~h}$ of static or dynamic culture. Data are reported as mean value \pm SEM of six coverslips from two independent experiments. ${ }^{*} p<0.05$ and ${ }^{* *} p<0.01$.

as mean \pm SEM of three independent biological replicates, unless otherwise stated. To compare the influences of cell culture conditions over time in a viability assay, two-way ANOVA was used followed by Tukey's multiple comparison test within the same cell seeding density. Student's $t$-test was performed within the same time point, when comparing two data sets during gene expression analysis. To compare the influences of the osteogenic cocktail and mechanical stimulation within the same time point, two-way ANOVA was used followed by Tukey's multiple comparison test. $P$ values less than 0.05 were accepted as significant.

\section{Results and Discussion}

Culturing cells within a controlled dynamic environment, where tightly regulated medium perfusion flow sustains cell survival and proliferation, was implemented in this work using an original elementary perfusion bioreactor system. 


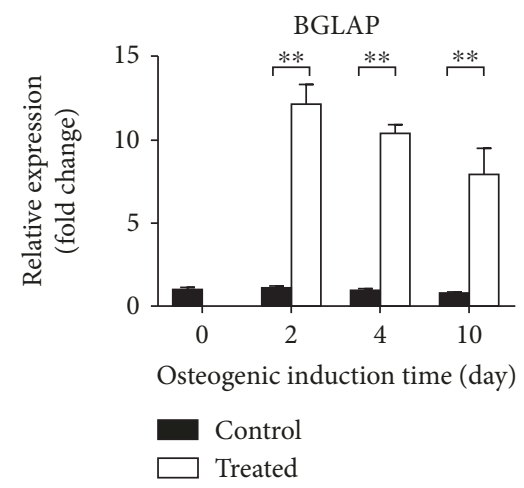

(a)

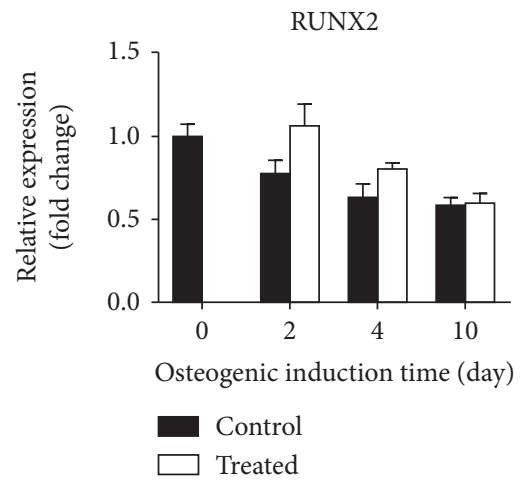

(d)

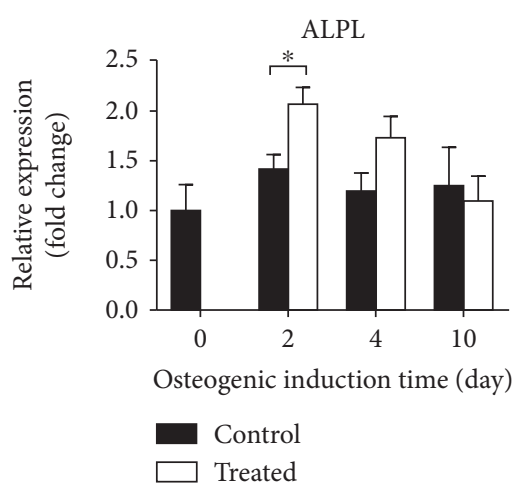

(b)

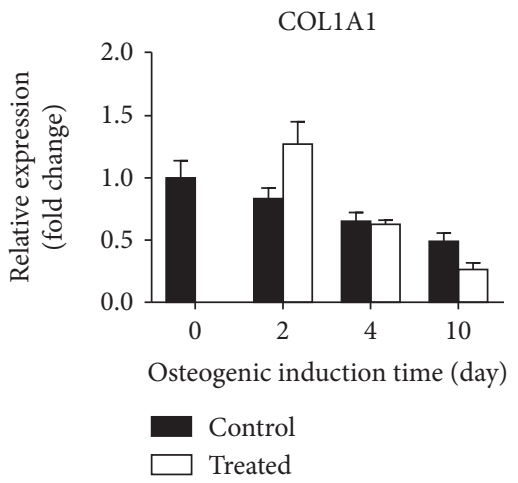

(e)

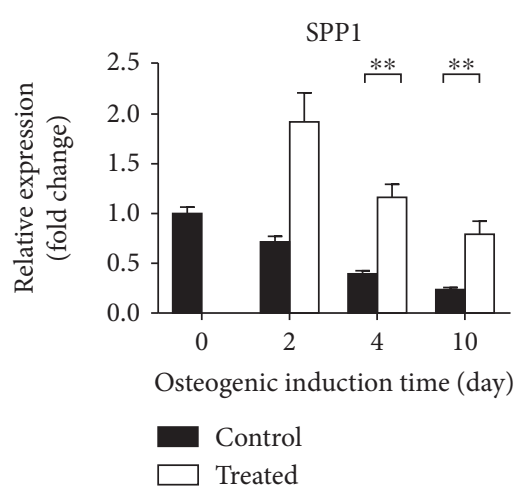

(c)

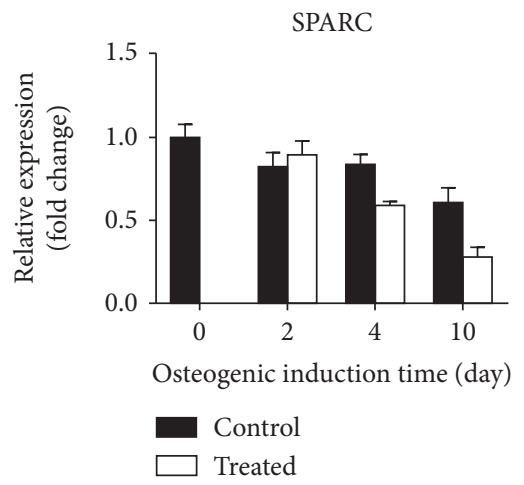

(f)

FIGURE 5: Induction of osteogenic gene expression under standard static cell culture condition conditions. qPCR analysis of osteogenic markers (BGLAP, ALPL, SPP1, RUNX2, COL1A1, and SPARC) was performed on L88/5 cells stimulated with the osteogenic cocktail (20 nM 1 $\alpha, 25$-dihydroxyvitamin D3, $50 \mu \mathrm{M}$ L-ascorbic acid 2-phosphate, and $10 \mathrm{mM} \beta$-glycerophosphate) up to 10 days. B2M and GAPDH were used as reference genes $\left(2^{-\Delta \Delta C T}\right.$ method). Fold changes from control untreated cells at day 0 were calculated. All data are reported as mean \pm SEM of four biological replicates. ${ }^{*} p<0.05$ and ${ }^{* *} p<0.01$.

Moreover, a significantly higher and faster upregulation of an osteogenic marker signature was induced when the perfusion flow stimulation was administered to L88/5 cells treated with an accredited osteogenic cocktail.

3.1. Effect of Perfusion on Cell Proliferation. L88/5 cells were seeded overnight on glass coverslips before their transfer into custom UV-irradiated sterile PMMA cell culture plates. Cell viability was evaluated after 48 and $72 \mathrm{~h}$ in either static or dynamic culture condition. Three different cell seeding densities (5000, 10,000, and 20,000 cells $/ \mathrm{cm}^{2}$ ) were tested. At higher levels $\left(10,000\right.$ and 20,000 cells $\left./ \mathrm{cm}^{2}\right)$ of cell density, the dynamic cell culture regimen allowed the proliferation of about $20 \%$ more cells than the static condition at the later (72 h) time point (Figure 4, grey and white bars, $p<0.05$ ), suggesting that in a high-density cell culture, locally reduced nutrient availability and waste product accumulation act as factors limiting cell proliferation $[1,11,12]$. Parallel cultures in standard polystyrene plates (Figure 4, black bars) were carried out as a control condition to rule out any effect of PMMA plates themselves over the basal proliferation capacity of the L88/5 cell line. No difference in cell viability was detected between standard polystyrene and PMMA plates confirming the biocompatibility of the material [9] and of the plate fabrication process.
3.2. Osteogenic Differentiation in Standard Cell Culture Condition. Osteogenic potential of L88/5 cells [13, 14] cultured in standard polystyrene culture plates was verified reproducing the treatment condition published in [15]; thus, upon administration of an osteogenic cocktail (20 nM 1 $\alpha, 25-$ dihydroxyvitamin D3, $50 \mu \mathrm{M}$ L-ascorbic acid 2-phosphate, and $10 \mathrm{mM} \beta$-glycerophosphate). Gene expression analysis of osteogenic markers was performed at the 2-, 4-, and 10day time points and reported in Figure 5. Osteocalcin (BGLAP) expression level was steadily $>10$-fold compared to its respective control at all the time points tested. A significant 1.5-fold upregulation of alkaline phosphatase (ALPL) gene was scored in cells treated for 2 days, whereas its level of expression became comparable in treated vs. control cells at the later time points (4 and 10 days). On the other hand, the osteopontin (SPP1) mRNA level was significantly higher (about 3-fold) in 4- and 10-day treated cells than in their respective time point control level. The osteogenic markers runt-related transcription factor 2 (RUNX2), collagen type I (COL1A1), and osteonectin (SPARC) were not significantly affected by the treatment. L88/5 cells have been proposed as an easy and inexpensive model of the human bone marrow cell line $[13,14]$, displaying osteogenic phenotype commitment when appropriately stimulated [15]. The gene expression profile identified in this study highlights that L88/5 


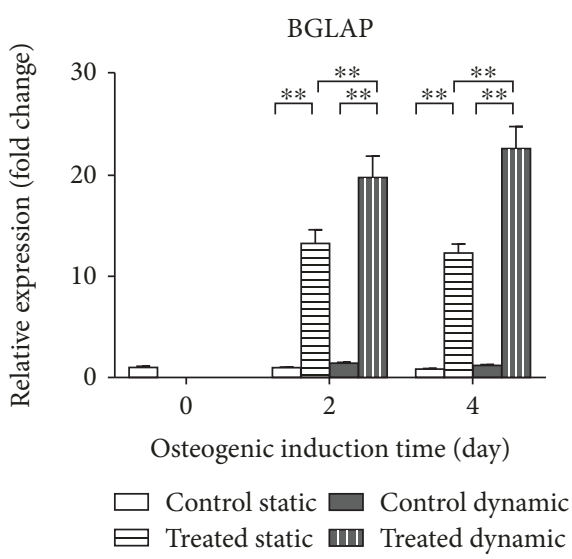

(a)

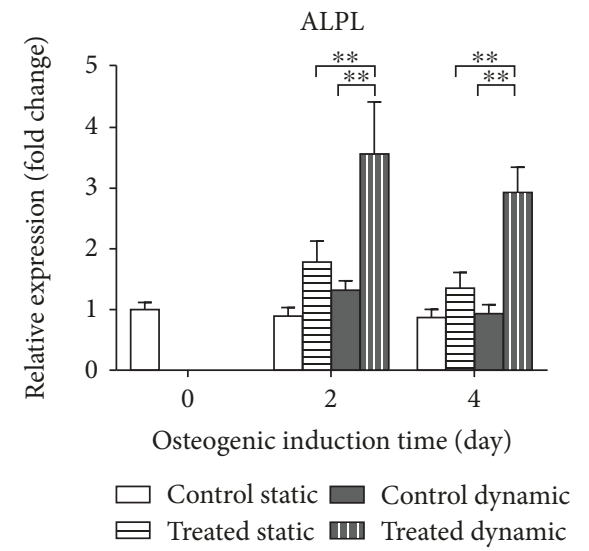

(b)

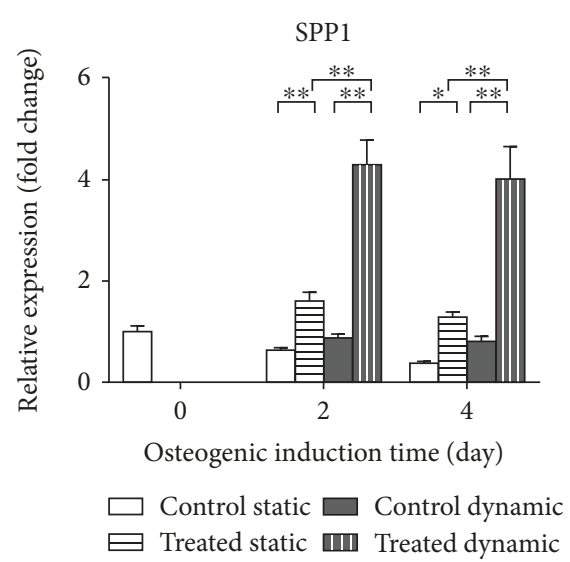

(c)

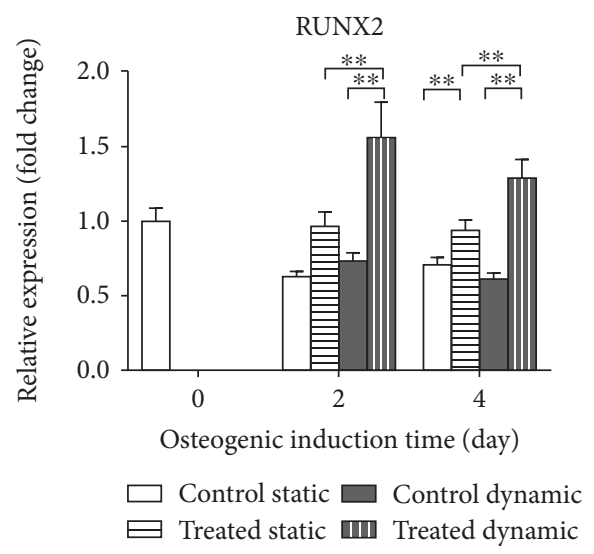

(d)

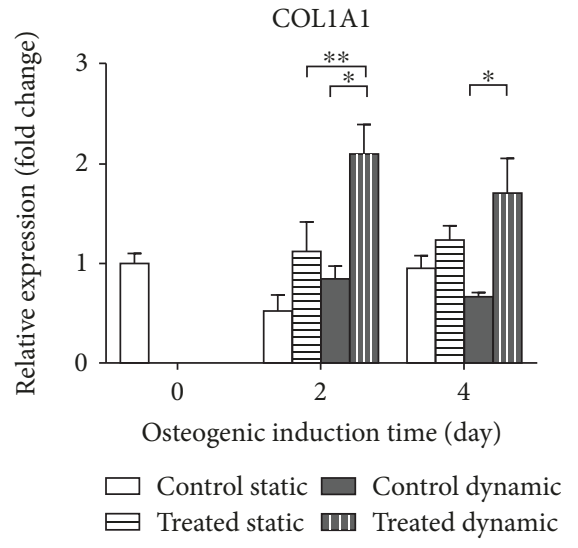

(e)

FIGURE 6: Effect of osteogenic induction on gene expression comparing standard static and dynamic cell culture conditions. qPCR analysis of osteogenic markers (BGLAP, ALPL, SPP1, RUNX2, and COL1A1) was performed on L88/5 cells stimulated with the osteogenic cocktail (20 nM 1 $\alpha$,25-dihydroxyvitamin D3, $50 \mu \mathrm{M} \mathrm{L}$-ascorbic acid 2-phosphate, and $10 \mathrm{mM} \beta$-glycerophosphate) for 2 and 4 days under static and dynamic cell culture conditions. B2M and GAPDH were used as reference genes ( $2^{-\Delta \Delta C T}$ method). Fold changes from control untreated cells at day 0 were calculated. All data are reported as mean \pm SEM of three biological replicates. ${ }^{*} p<0.05$ and ${ }^{* * *} p<0.01$.

cells express basal levels of typical active genes in osteogenic precursors, such as BGLAP, SPP1, or COL1A1, as reported by other groups that also consistently detected the expected lack of expression of collagen types II and III [14]. Our and other published results accredit this cell line and the administered osteogenic cocktail as good experimental models of early osteogenic commitment. The effect induced by the flow perfusion applied via our bioreactor system was thus compared with this static control. Notably, as an additional advantage, L88/5 cells that were originally genetically modified to include the viral DNA sequences of simian virus 40 (SV40) [16] have acquired a short replication time and a clonogenic ability to maintain the same phenotype over passages $[13,14]$. These features reduce donor variability and exclude ethical issues associated with the use of primary human MSCs, supporting their use in the validation of standard in vitro protocols and differentiation strategies, such as the perfusion system described in this study.

\subsection{Effect of Perfusion on Osteogenic Cocktail-Treated Cells.} To investigate the effect of perfusion on osteogenic L88/5 cell potential, gene expression analysis of bone specific markers was performed comparing static vs. dynamic culture conditions. Briefly, cells were grown to confluence on glass coverslips and transferred into custom PMMA plates either without, or with communicating wells to allow media recirculation when perfusion was applied. Cells were then stimulated with the mentioned osteogenic cocktail and collected at day 2 and 4 posttreatment. Gene expression analysis showed that at both the time points studied, all the osteogenic markers were significantly upregulated in the cells cultured in the dynamic condition (Figure 6). In detail, when perfusion was present, both late (BGLAP, ALPL, and SPP1) and early (RUNX2 and COL1A1) osteogenic markers were significantly overexpressed, with respect to the static control condition (about >13-, 3-, 5-, 2-, and 1.5-fold, respectively, $p<0.05)$. The fold-change increase was maintained over the 4 days of induction. In this culture configuration, the standard static condition determines a significant increase of only BGLAP and SPP1 genes 2 days posttreatment (13.6- and 2.5-fold, respectively, compared to control cells; Figure 6). On the other hand, perfusion was also able to determine a significant upregulation of the early markers RUNX2 and COL1A1 already at 2 days of induction whereas 


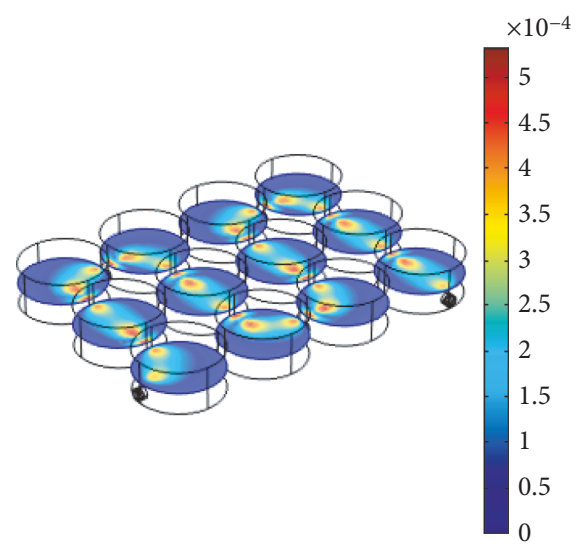

$y_{\pi}^{z} x$
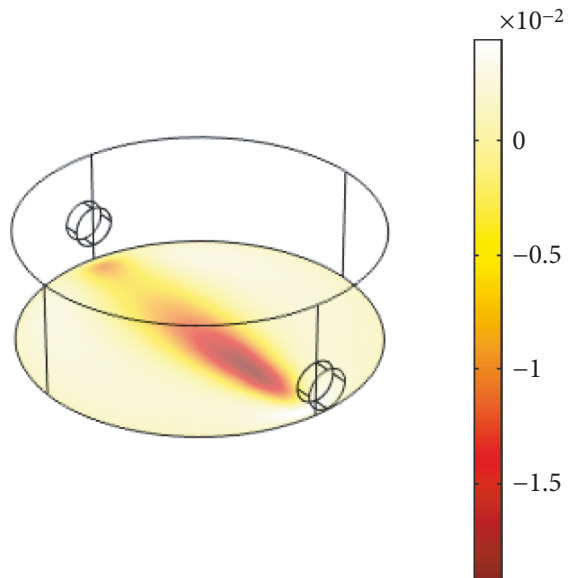

$y_{\mathbb{R}}^{z} x$

(b)

(a)

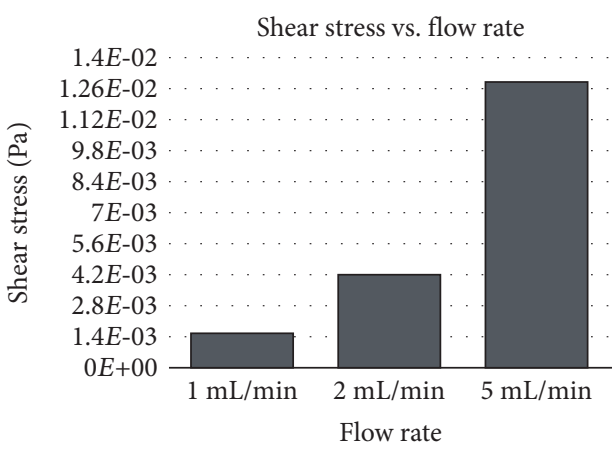

(c)

FIGURE 7: In silico evaluation of the velocity profile in the communicating well plate (a) and of the shear stress in a single well (b) at a flow rate of $1 \mathrm{~mL} / \mathrm{min}$. (c) In silico evaluation of the shear stress values corresponding to 1,2 , and $5 \mathrm{~mL} / \mathrm{min}$ flow rates.

prolonged osteogenic induction up to 10 days missed to produce a comparable effect in standard static cell culture, as shown in Figure 5. Moreover, when the perfusion was present, the osteogenic cocktail-induced upregulation of all the osteogenic genes was significantly higher, compared to the static cell culture condition, indicating that the dynamic regimen improves the early osteogenic commitment of this cell line (Figure 6). These results well compare with published evidences in other experimental settings, as reviewed in $[17,18]$, highlighting how flow perfusion determines a relevant effect in terms of level and speed of phenotype commitment, although variations in cell types, culture conditions, and experimental platforms used increase the complexity of the variables to take into account.

3.4. In Silico Evaluation of Perfusion Flow Physics. An in silico FEM evaluation was performed to investigate fluid velocity profile (Figure $7(\mathrm{a})$ ), shear stress (Figures $7(\mathrm{~b})$ and $7(\mathrm{c})$ ), nutrient consumption, and waste production (Figure 8). The whole geometry of the PMMA custom-milled communicating well plates was used to evaluate the perfusion velocity profile, while only a single well was considered to evaluate shear stress, nutrient consumption, and waste production, in order to save computational time. Although with an imposed flow rate of $1 \mathrm{~mL} / \mathrm{min}$ fluid velocity is slightly increased at the well intercommunications, it is maintained within the same magnitude order $\left(10^{-4} \mathrm{~m} / \mathrm{s}\right)$ along the whole perfusion path (Figure $7(\mathrm{a})$ ). Flow rate values of 1, 2, and $5 \mathrm{~mL} / \mathrm{min}$ were tested (Figure $7(\mathrm{c})$ ) aiming to estimate the shear stress value occurring at the bottom of the custom PMMA well. Notably, a flow rate of $5 \mathrm{~mL} / \mathrm{min}$ entails an average shear stress value of $1.3 \cdot 10^{-2} \mathrm{~Pa}$. On the other hand, flow rates of $2 \mathrm{~mL} / \mathrm{min}$ and $1 \mathrm{~mL} / \mathrm{min}$ entail average shear stress values of $4.2 \cdot 10^{-3} \mathrm{~Pa}$ and $1.6 \cdot 10^{-3} \mathrm{~Pa}$, respectively; these values are in the range able to induce osteogenic commitment of human MSCs [19, 20].

Figure 8 shows the results of a numerical analysis of nutrient consumption and waste production in static vs. dynamic cell cultures during a 3-day span imposing a flow rate of $1 \mathrm{~mL} / \mathrm{min}$. Figures $8(\mathrm{a})$ and 8 (b) illustrate a qualitative evaluation of their spatial distributions within a single well. In the static condition (Figure 8(a)), lower nutrient and higher waste concentration values are present in the proximity of the cell layer, compared to the peripheral area. On the other hand, in the dynamic condition (Figure 8(b)), an homogeneous nutrient/waste concentration distribution is present, suggesting that perfusion enhances diffusive exchanges. Figure 8(c) shows a quantitative evaluation 

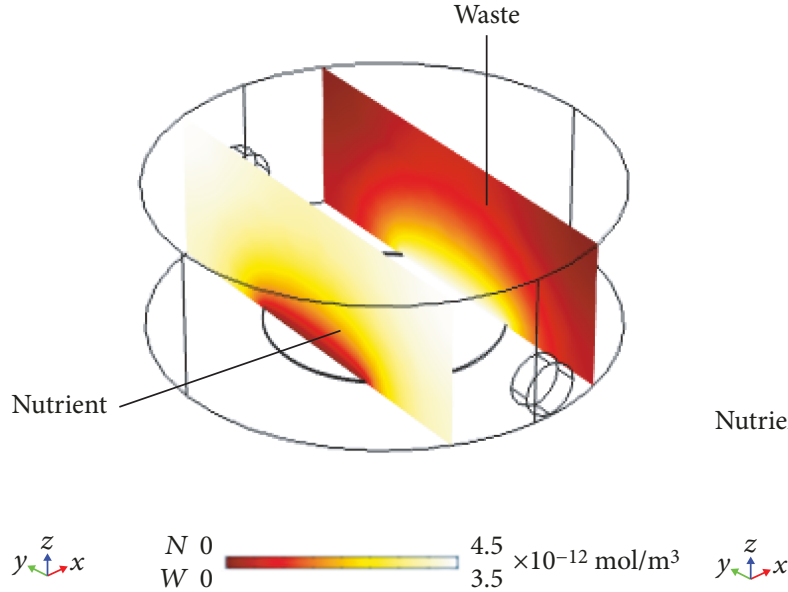

(a)
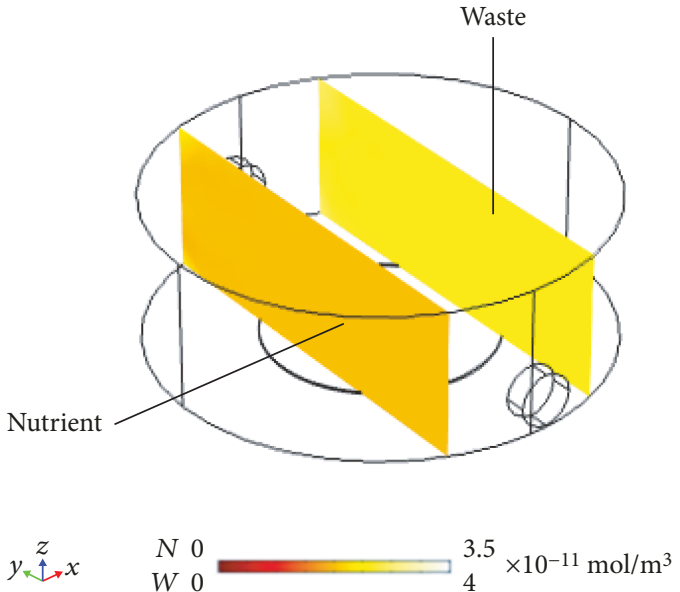

(b)

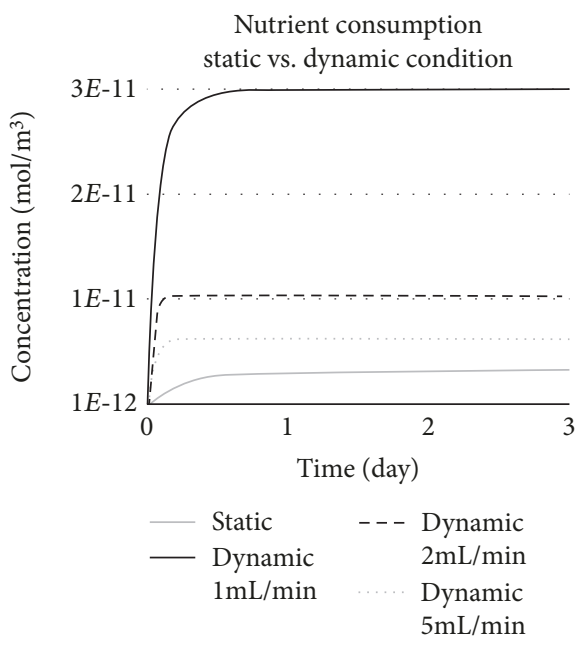

(c)

FIGURE 8: In silico qualitative evaluation of nutrient consumption and waste production distributions within the well volume in static (a) and dynamic (b) conditions; $N$, nutrient consumption; $W$, waste production. (c) Quantitative evaluation of nutrient consumption in static (grey line) vs. dynamic (black line) conditions in the proximity of the cell layer over time (3 days). $\Delta$, time to reach the $95 \%$ of the regimen value.

performed, at different flow rates, to determine the amount of nutrient consumption occurring when static vs. dynamic cell cultures are compared. The timedependent analysis shows that in dynamic conditions (i) a faster consumption rate is present, as $95 \%$ of the steadystate value is reached in $7 \mathrm{~h}$ when imposing a flow rate of $1 \mathrm{~mL} / \mathrm{min}$, compared with $21 \mathrm{~h}$ required for the static condition (Figure 8(c)); (ii) a higher (up to 7.8-fold with respect to static condition) nutrient consumption occurs (Figure $8(\mathrm{c})$ ); and (iii) a lower flow rate $(1 \mathrm{~mL} / \mathrm{min})$ is associated with higher nutrient consumption, compared with the effects produced by 2 and $5 \mathrm{~mL} / \mathrm{min}$ flow rates. These results are in line with the finding reported in [21], suggesting that higher flow rates could interfere with diffusive exchanges of nutrient and waste removal. Evidences in the literature show how perfusion bioreactor systems are used to apply fluid flow and to improve mass transport between medium and cells. Perfusion affects cell proliferation and improves osteogenic differentiation of human embryonic stem cell-derived mesenchymal progenitors induced by an osteogenic medium
[7]. Fluid shear stress coupled with osteogenic supplements enhances MSC osteogenic differentiation as confirmed by an increased production and improved organization of the extra cellular matrix (ECM) [3]. In summary, the $1 \mathrm{~mL} / \mathrm{min}$ flow rate used appears as an optimal value in order to obtain a shear stress compatible with osteogenic commitment and higher nutrient consumption.

\section{Conclusion}

Traditional strategies for stem cell (SC) differentiation rely on soluble molecules, such as growth factors and cytokines, that induce a cascade of signalling pathways associated with phenotype commitment. The perfusion system here described shows promising advantages in promoting the early osteogenic commitment of human stromal bone marrow cells. The overexpression of osteogenic markers, indicative of the early phenotype change, is likely to be associated with enhanced diffusive exchanges induced by perfusion, that together with increased waste removal, could 
improve the transport of nutrients and soluble osteogenic stimuli toward cells, as supported by in silico data. In summary, increased cell proliferation and enhanced early phenotype commitment indicate that dynamic cell culture conditions, delivered via bioreactor systems, produce an enhanced in vitro environment for both basic and translational research in tissue engineering and regenerative medicine. Easy to use, cheap, and versatile devices, such as the one described here, are expected to become a new standard in cell culture, both in research and in clinical laboratories.

\section{Data Availability}

The data used to support the findings of this study are available from the corresponding author upon request.

\section{Disclosure}

Preliminary data have been presented at the $8^{\circ}$ I.S.Mu.L.T. Congress, Salerno, Italy, last 30th November-1st December 2018.

\section{Conflicts of Interest}

The authors declare no conflict of interest.

\section{Authors' Contributions}

AP, JL, and EG designed and planned the study. JL designed and built the bioreactor prototype and performed the in silico analysis. AP and GF performed the in vitro biological analysis. AP, JL, and EG are responsible for data analysis and manuscript writing. All authors approved the final manuscript. AP and JL contributed equally to this work.

\section{Acknowledgments}

The authors thank Balzoni Vittore \& Figli s.n.c. (http:// www.bv1.it) for kindly providing the PMMA custommilled plates used in this study. Professor Jeanette Maier, Department of Biomedical and Clinical Sciences "L. Sacco," University of Milan, Milan, Italy, kindly donated the L88/5 cell line.

\section{References}

[1] D. Schop, F. W. Janssen, L. D. S. van Rijn et al., "Growth, metabolism, and growth inhibitors of mesenchymal stem cells," Tissue Engineering Part A, vol. 15, no. 8, pp. 18771886, 2009.

[2] K. Bilodeau and D. Mantovani, "Bioreactors for tissue engineering: focus on mechanical constraints. A comparative review," Tissue Engineering, vol. 12, no. 8, pp. 23672383, 2006.

[3] R. M. Delaine-Smith, S. MacNei, and G. C. Reilly, "Matrix production and collagen structure are enhanced in two types of osteogenic progenitor cells by a simple fluid shear stress stimulus," European Cells and Materials, vol. 24, no. 24, pp. 162-174, 2012.
[4] A. B. Yeatts and J. P. Fisher, "Bone tissue engineering bioreactors: dynamic culture and the influence of shear stress," Bone, vol. 48, no. 2, pp. 171-181, 2011.

[5] J. Lovecchio, S. M. Jónsdóttir-Buch, G. K. Einarsdóttir et al., "Assessment of a perfusion bioreactors system using $\mu \mathrm{CT}$ technology and 3D modeling methods," Biomedizinische Technik, vol. 59, pp. S302-S305, 2014.

[6] G. D. Porta, B.-N. B. Nguyen, R. Campardelli, E. Reverchon, and J. P. Fisher, "Synergistic effect of sustained release of growth factors and dynamic culture on osteoblastic differentiation of mesenchymal stem cells," Journal of Biomedical Materials Research Part A, vol. 103, no. 6, pp. 2161-2171, 2015.

[7] B. Bhaskar, R. Owen, H. Bahmaee, P. S. Rao, and G. C. Reilly, "Design and assessment of a dynamic perfusion bioreactor for large bone tissue engineering scaffolds," Applied Biochemistry and Biotechnology, vol. 185, no. 2, pp. 555-563, 2018.

[8] F. Langenbach and J. Handschel, "Effects of dexamethasone, ascorbic acid and $\beta$-glycerophosphate on the osteogenic differentiation of stem cells in vitro," Stem Cell Research \& Therapy, vol. 4, no. 5, p. 117, 2013.

[9] S. Samavedi, L. K. Poindexter, M. Van Dyke, and A. S. M. Goldstein, "Synthetic biomaterials for regenerative medicine applications," in Chapter 7 in Regenerative Medicine Applications in Organ Transplantation, G. Orlando, Ed., pp. 81-99, Academic Press, 2014.

[10] T. J. Spencer, L. A. Hidalgo-Bastida, S. H. Cartmell, I. Halliday, and C. M. Care, "In silico multi-scale model of transport and dynamic seeding in a bone tissue engineering perfusion bioreactor," Biotechnology and Bioengineering, vol. 110, no. 4, pp. 1221-1230, 2013.

[11] X. Chen, H. Xu, C. Wan, M. McCaigue, and G. Li, "Bioreactor expansion of human adult bone marrow-derived mesenchymal stem cells," Stem Cells, vol. 24, no. 9, pp. 2052-2059, 2006.

[12] G. Higuera, D. Schop, F. Janssen, R. van DijkhuizenRadersma, T. van Boxtel, and C. A. van Blitterswijk, "Quantifying in vitro growth and metabolism kinetics of human mesenchymal stem cells using a mathematical model," Tissue Engineering Part A, vol. 15, no. 9, pp. 2653-2663, 2009.

[13] K. Thalmeier, P. Meissner, G. Reisbach, M. Falk, A. Brechtel, and P. Dörmer, "Establishment of two permanent human bone marrow stromal cell lines with long-term post irradiation feeder capacity," Blood, vol. 83, pp. 1799-1807, 1994.

[14] K. Thalmeier, P. Meissner, S. Moosmann, S. Sagebiel, I. Wiest, and R. Huss, "Mesenchymal differentiation and organ distribution of established human stromal cell lines in NOD/SCID mice," Acta Haematologica, vol. 105, no. 3, pp. 159-165, 2001.

[15] A. Cazzaniga, J. A. M. Maier, and S. Castiglioni, "Impact of simulated microgravity on human bone stem cells: new hints for space medicine," Biochemical and Biophysical Research Communications, vol. 473, no. 1, pp. 181-186, 2016.

[16] K. Thalmeier and P. Dörmer, "Stromal cell lines from human bone marrow and their use," p. 19, 1997, U.S. Patent US005658761.

[17] G. Yourek, S. M. McCormick, J. J. Mao, and G. C. Reilly, "Shear stress induces osteogenic differentiation of human mesenchymal stem cells," Regenerative Medicine, vol. 5, no. 5, pp. 713-724, 2010.

[18] R. J. McCoy and F. J. O'Brien, "Influence of shear stress in perfusion bioreactor cultures for the development of threedimensional bone tissue constructs: a review," Tissue Engineering Part B: Reviews, vol. 16, no. 6, pp. 587-601, 2010. 
[19] J. R. Vetsch, D. C. Betts, R. Müller, and S. Hofmann, "Flow velocity-driven differentiation of human mesenchymal stromal cells in silk fibroin scaffolds: a combined experimental and computational approach," PLoS One, vol. 12, no. 7, article e0180781, 2017.

[20] F. Zhao, B. van Rietbergen, K. Ito, and S. Hofmann, "Flow rates in perfusion bioreactors to maximise mineralisation in bone tissue engineering in vitro," Journal of Biomechanics, vol. 79, pp. 232-237, 2018.

[21] M. Devarapalli, B. J. Lawrence, and S. V. Madihally, "Modeling nutrient consumptions in large flow-through bioreactors for tissue engineering," Biotechnology and Bioengineering, vol. 103, no. 5, pp. 1003-1015, 2009. 


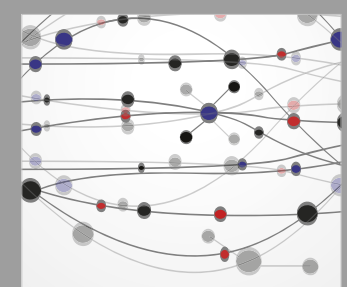

The Scientific World Journal
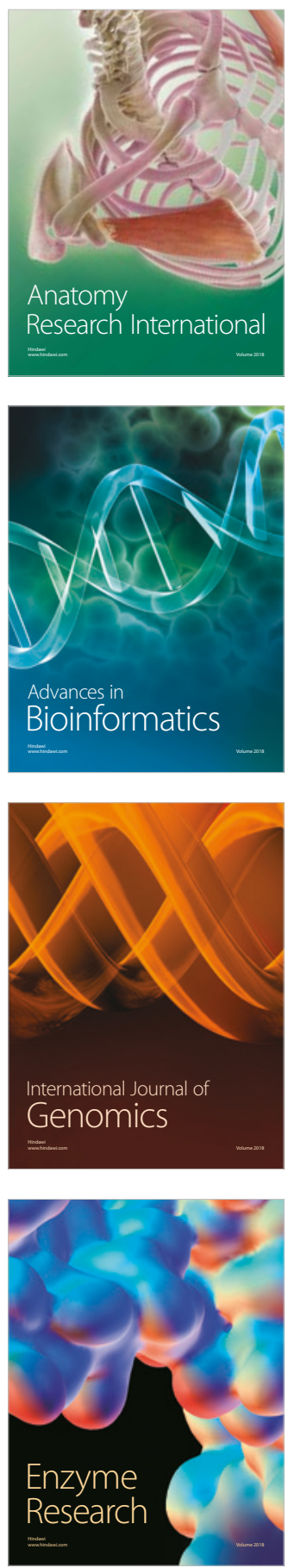
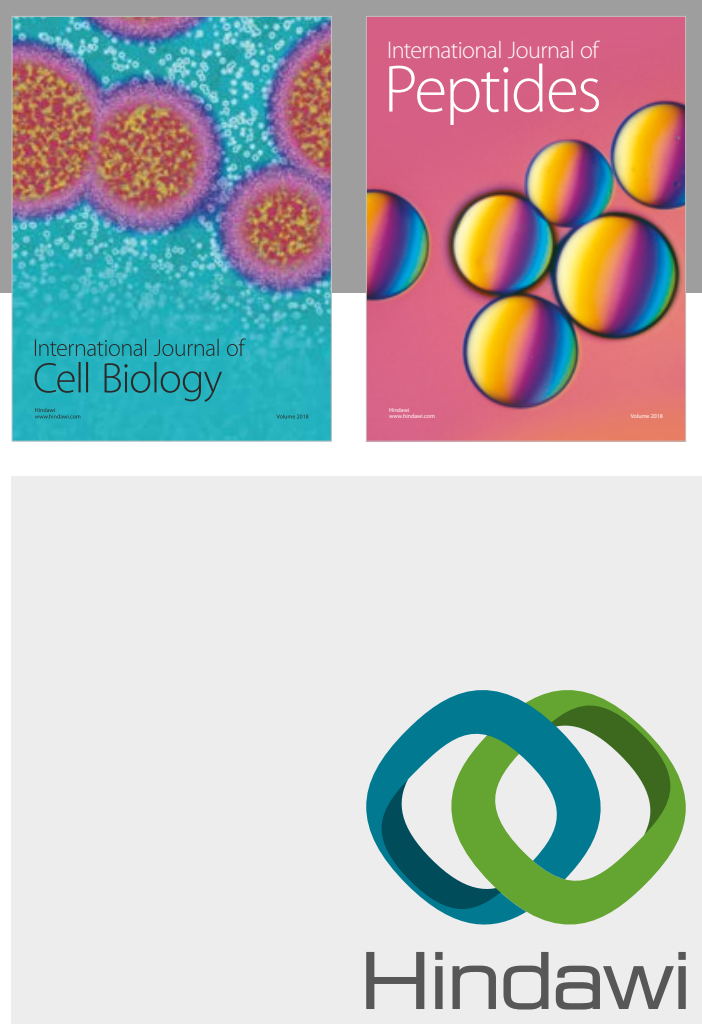

Submit your manuscripts at

www.hindawi.com
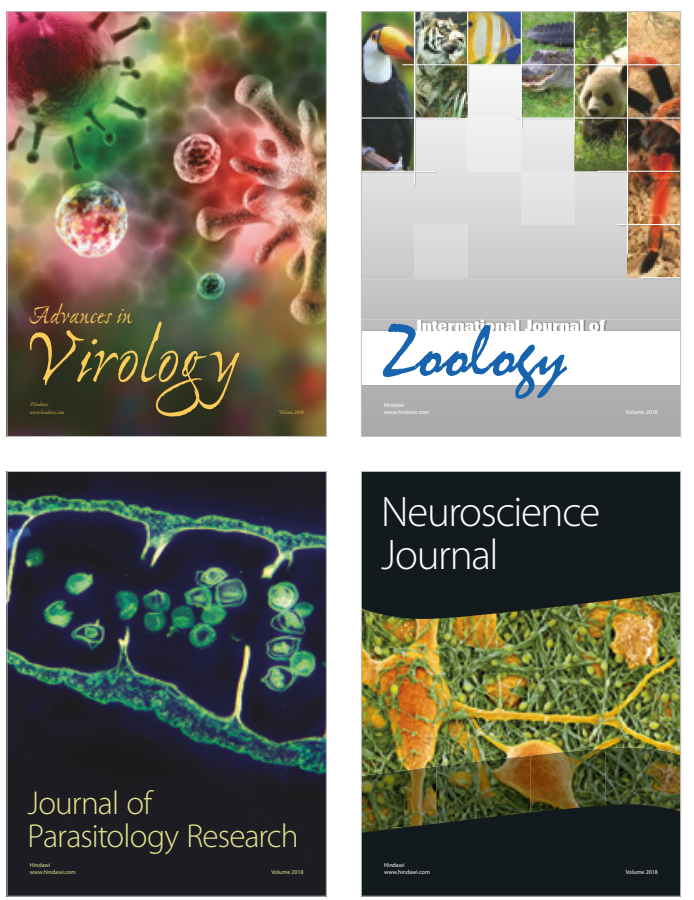
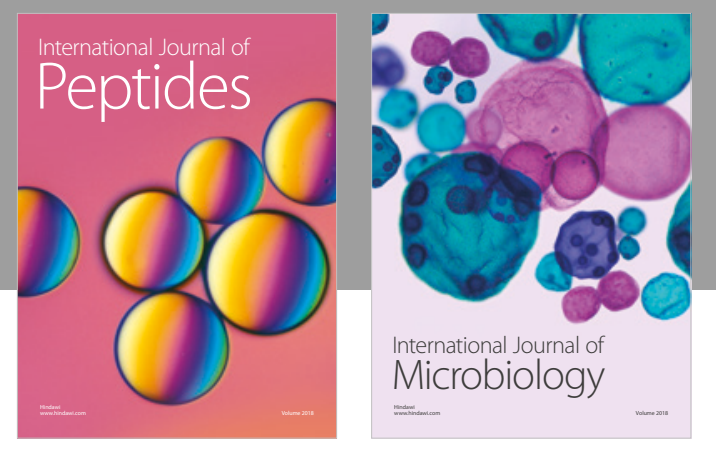

nternational Journal of Microbiology
Journal of
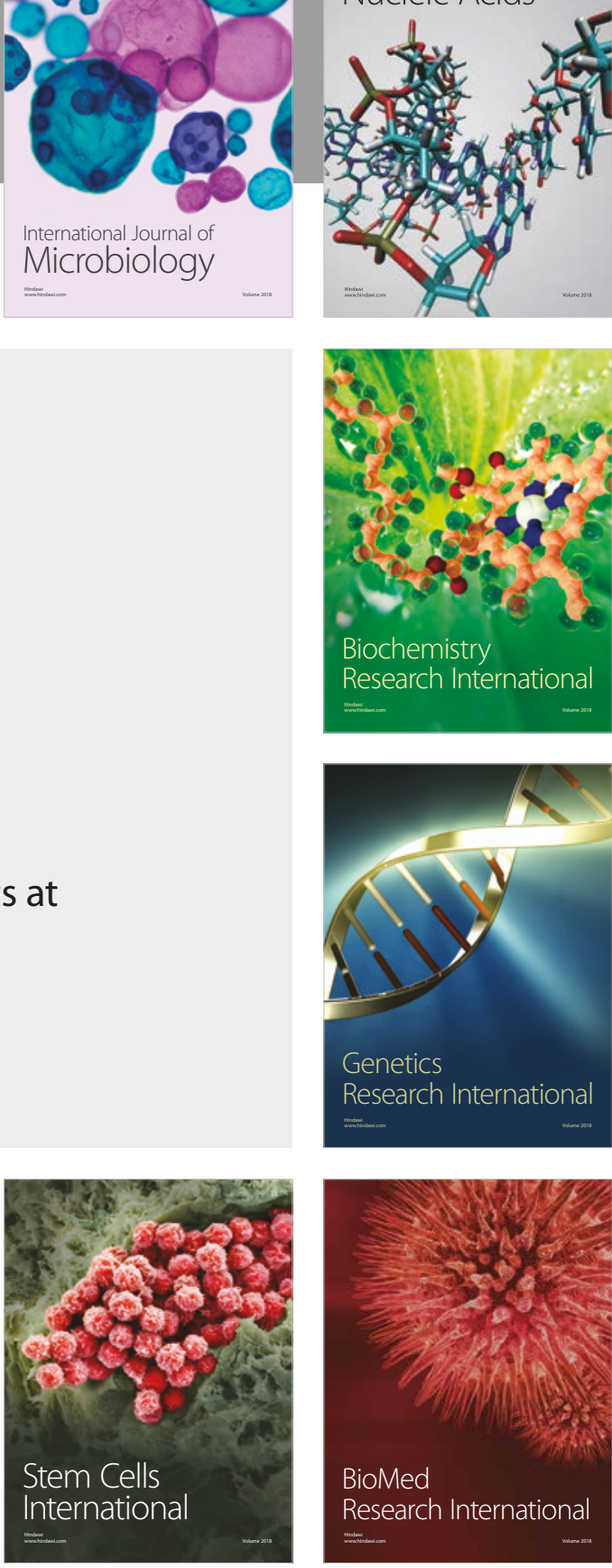
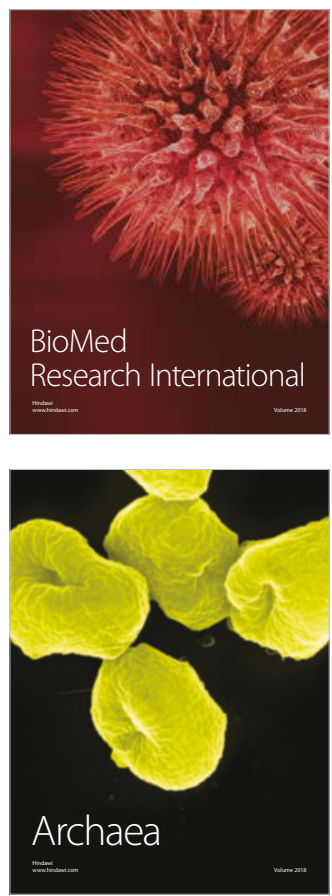